\title{
Ablacja prawostronnej i lewostronnej drogi wolnej nawrotnego węzłowego częstoskurczu przedsionkowo-komorowego
}

\author{
Ablation of right-sided and left-sided slow pathway of atrioventricular \\ nodal reentrant tachycardia
}

\author{
Paweł Wałek ${ }^{1}$, Maciej Młodnicki ${ }^{1}$, Przemysław Dąbkowski ${ }^{1}$, \\ Beata Wożakowska-Kapłon ${ }^{1,2}$ \\ ${ }^{1}$ Świętokrzyskie Centrum Kardiologii Wojewódzkiego Szpitala Zespolonego w Kielcach \\ ${ }^{2}$ Wydział Lekarski Nauk o Zdrowiu Uniwersytetu Jana Kochanowskiego w Kielcach
}

\section{Streszczenie}

Przedstawiono ablację prawo- i lewostronnej drogi wolnej nawrotnego węzłowego częstoskurczu przedsionkowo-komorowego.

Słowa kluczowe: ablacja, częstoskurcz węzłowy nawrotny przedsionkowo-komorowy, lewostronna droga wolna

Folia Cardiologica 2017; 12, 5: 497-500

\section{Wstęp}

Nawroty węzłowy częstoskurcz przedsionkowo-komorowy (AVNRT, atrioventricular nodal reentrant tachycardia) to jedna z najczęściej spotykanych arytmii nadkomorowych. W postaci typowej, tj. wolno-szybkiej, celem ablacji jest droga wolna pętli częstoskurczu najczęściej zlokalizowana w dolnej części trójkąta Kocha. Szacuje się, że w około $1,8 \%$ przypadków droga wolna jest zlokalizowana po lewej stronie przegrody międzyprzedsionkowej [1]. W artykule przedstawiono przypadek skutecznej ablacji dróg wolnych zlokalizowanych po prawej i lewej stronie przegrody międzyprzedsionkowej.

\section{Opis przypadku}

Chora w wieku 66 lat, z udokumentowanymi napadami częstoskurczu z wąskimi zespołami QRS bez widocznego załamka $\mathrm{P}$ w powierzchniowym 12-odprowadzeniowym zapisie elektrokardiograficznym (EKG), została przyjęta w celu wykonania planowego badania elektrofizjologicznego (EPS, electrophysiology study). W wykonanym EPS zarejestrowano skok przewodzenia w węźle przedsionkowo-komorowym oraz podwójne nawrotne pobudzenia węzłowe. W trakcie EPS nie wyindukowano częstoskurczu z wąskimi zespołami QRS. Ze względu na wywiad udokumentowanego częstoskurczu z wąskimi zespołami QRS oraz cechy dualizmu przewodzenia w węźle przedsionkowo-komorowym zdecydowano o ablacji drogi wolnej węzła przedsionkowo-komorowego (AVN, atrioventricular nodal). W trakcie mapowania dolnej części trójkąta Kocha w miejscu potencjału drogi wolnej wykonano aplikacje prądu o częstotliwości radiowej (RF, radiofrequency) (30 W, $50^{\circ} \mathrm{C}$ ), uzyskując wolne pobudzenia węzłowe ze wstecznym przewodzeniem do przedsionka (ryc. 1, 2). Wykonano EPS, w którym stwierdzono utrzymujące się cechy dualizmu przewodzenia AVN (skok przewodzenia oraz podwójne nawrotne pobudzenia węzłowe). Zmapowano ujście i strop zatoki wieńcowej oraz okolice środkową prawostronną przegrody międzyprzedsionkowej. Jedynie w stropie zatoki wieńcowej

Adres do korespondencji: lek. Paweł Wałek, Świętokrzyskie Centrum Kardiologii, Wojewódzki Szpital Zespolony, ul. Grunwaldzka 45, 25-736 Kielce, tel. 413671 510, e-mail: pawel.walek@o2.pl 


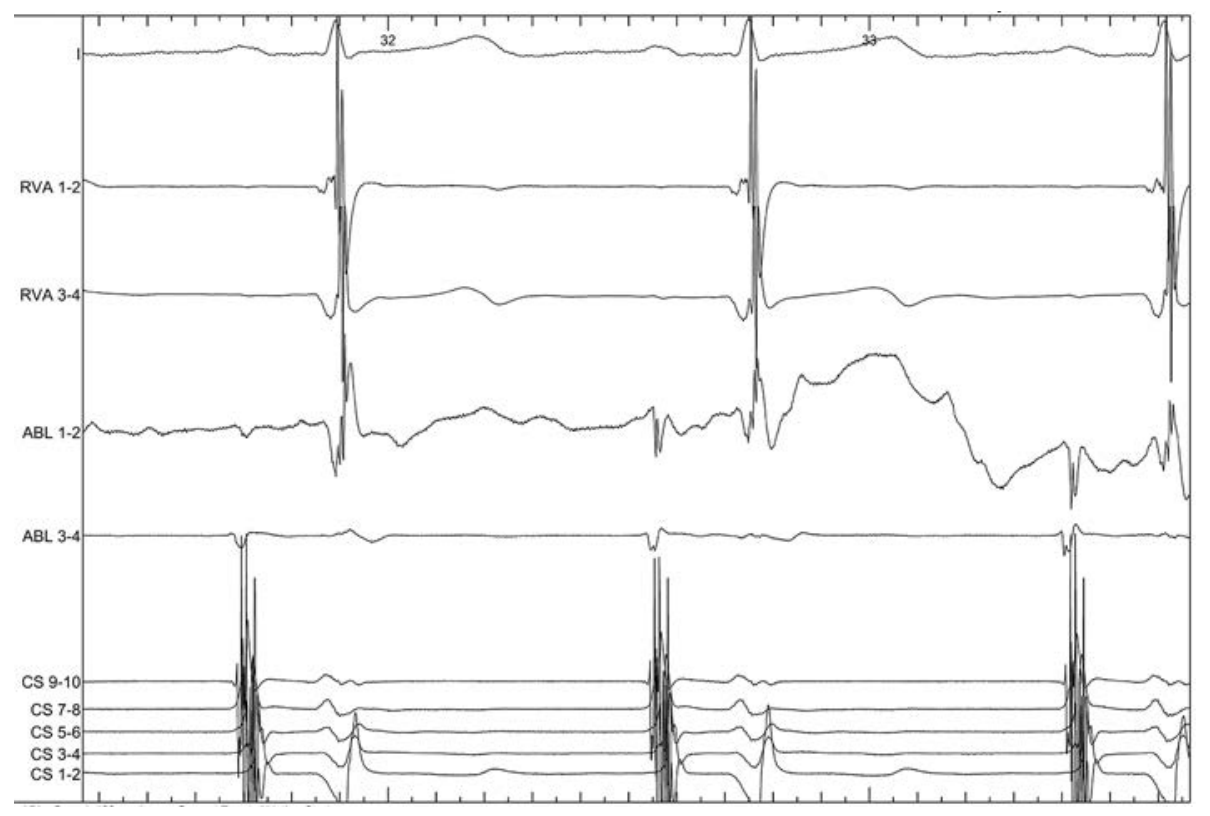

Rycina 1. Zapis wewnątrzsercowy - potencjał prawostronnej drogi wolnej węzła przedsionkowo-komorowego (AVN, atrioventricular nodal) zlokalizowanej w dolnej części trójkąta Kocha

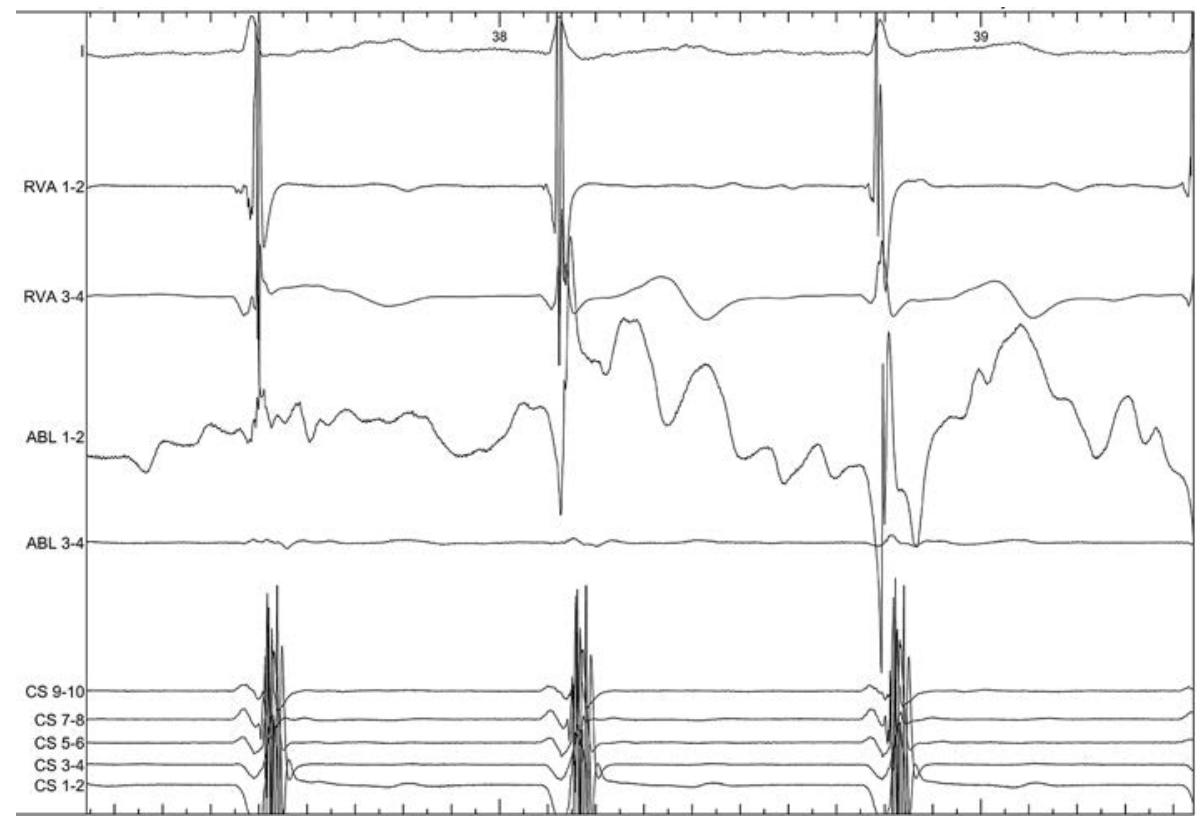

Rycina 2. Zapis wewnątrzsercowy - aplikacja prądu o częstotliwości radiowej (RF, radiofrequency) w miejscu prawostronnej drogi wolnej węzła przedsionkowo-komorowego (AVN, atrioventricular nodal); widoczne wolne pobudzenia węzłowe ze wstecznym przewodzeniem do przedsionków

uzyskano potencjały mogące odpowiadać drodze wolnej AVN. Wykonano aplikację w stropie ujścia zatoki wieńcowej, nie uzyskując pobudzeń węzłowych. Ponownie wykonano EPS, nadal rejestrując cechy dualizmu przewodzenia w węźle AVN. Przez drożny otwór owalny wprowadzono elektrodę ablacyjną do lewego przedsionka, rotując ją zgodnie z ruchem wskazówek zegara, a następnie mapując pierścień mitralny oraz lewoprzegrodową część AVN (ryc. 3). W dolno-tylnej części przegrody międzyprzedsionkowej, w okolicy pierścienia mitralnego, zlokalizowano potencjał 


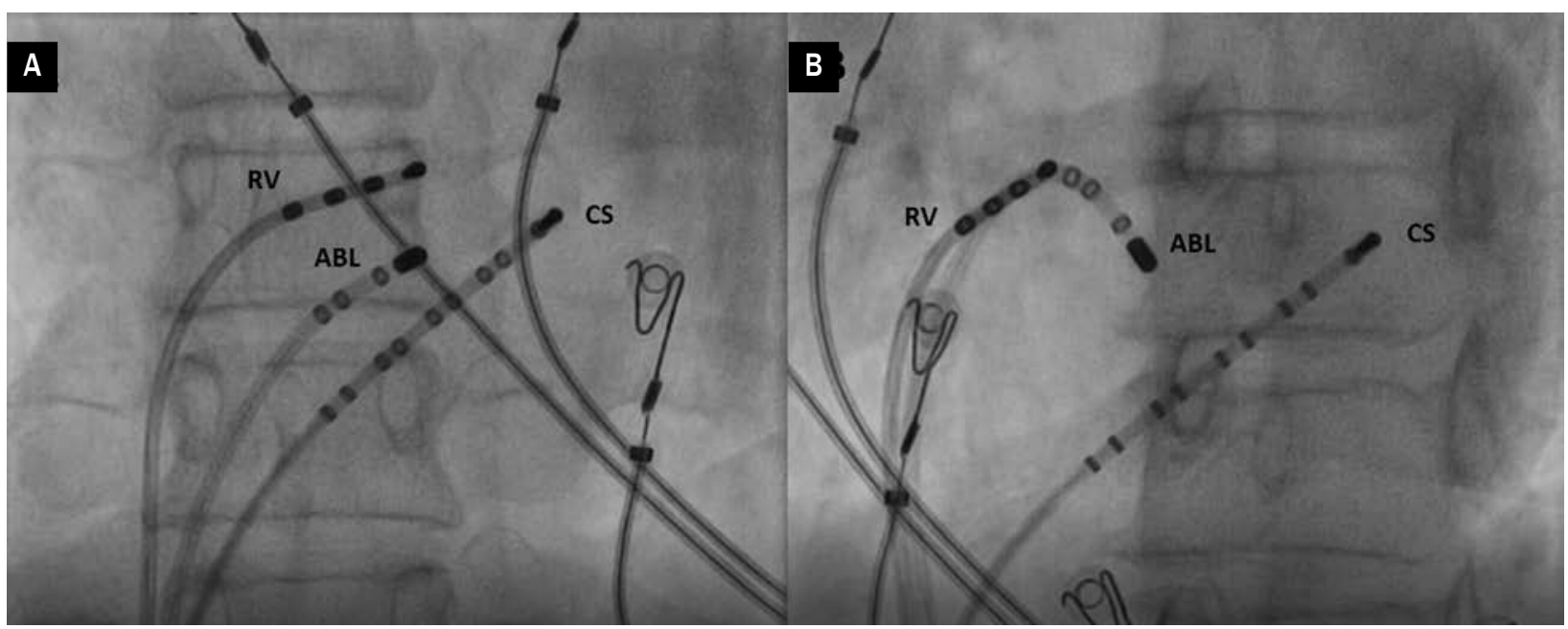

Rycina 3A, B. Fluoroskopia - ułożenie elektrod w trakcie mapowania lewostronnej drogi wolnej; A. Projekcja przednio-tylna (AP, anterior-posterior); B. Projekcja lewa przednia skośna (LAO, left anterior oblique) $30^{\circ}$; RV - elektroda 4-polowa umiejscowiona w miejscu na węzeł przedsionkowo-komorowego; ABL - elektroda ablacyjna (Stinger F, 7F, Bard); CS - elektroda 10-polowa umiejscowiona (płytko) w zatoce wieńcowej

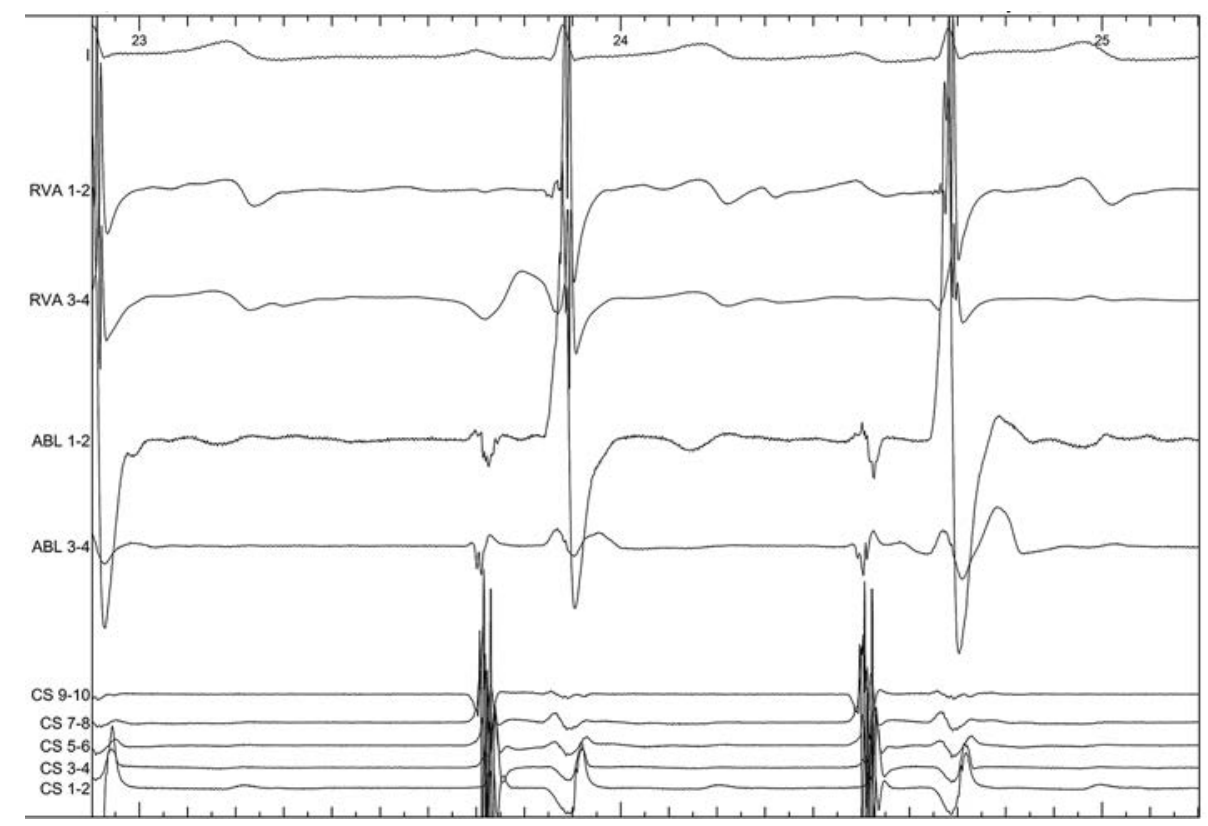

Rycina 4. Zapis wewnątrzsercowy - potencjał lewostronnej drogi wolnej węzła przedsionkowo-komorowego (AVN, atrioventricular nodal) zlokalizowany między dolno-tylną częścią przegrody międzyprzedsionkowej oraz pierścieniem mitralnym

drogi wolnej AVN (ryc. 4). Wykonano aplikację prądu RF (30 $\mathrm{W}, 50^{\circ} \mathrm{C}$ ) wyżej wspomnianej okolicy, rejestrując typowe wolne pobudzenia węzłowe ze wstecznym przewodzeniem do przedsionka (ryc. 5). Po ablacji wykonano EPS, w którym już nie rejestrowano cech dualizmu przewodzenia w AVN. W czasie trwającej pół roku obserwacji u chorej, niepod- danej leczeniu antyarytmicznemu, nie odnotowano żadnej arytmii ani kołatań serca.

\section{Konflikt interesów}

Autorzy deklarują brak konfliktu interesów. 


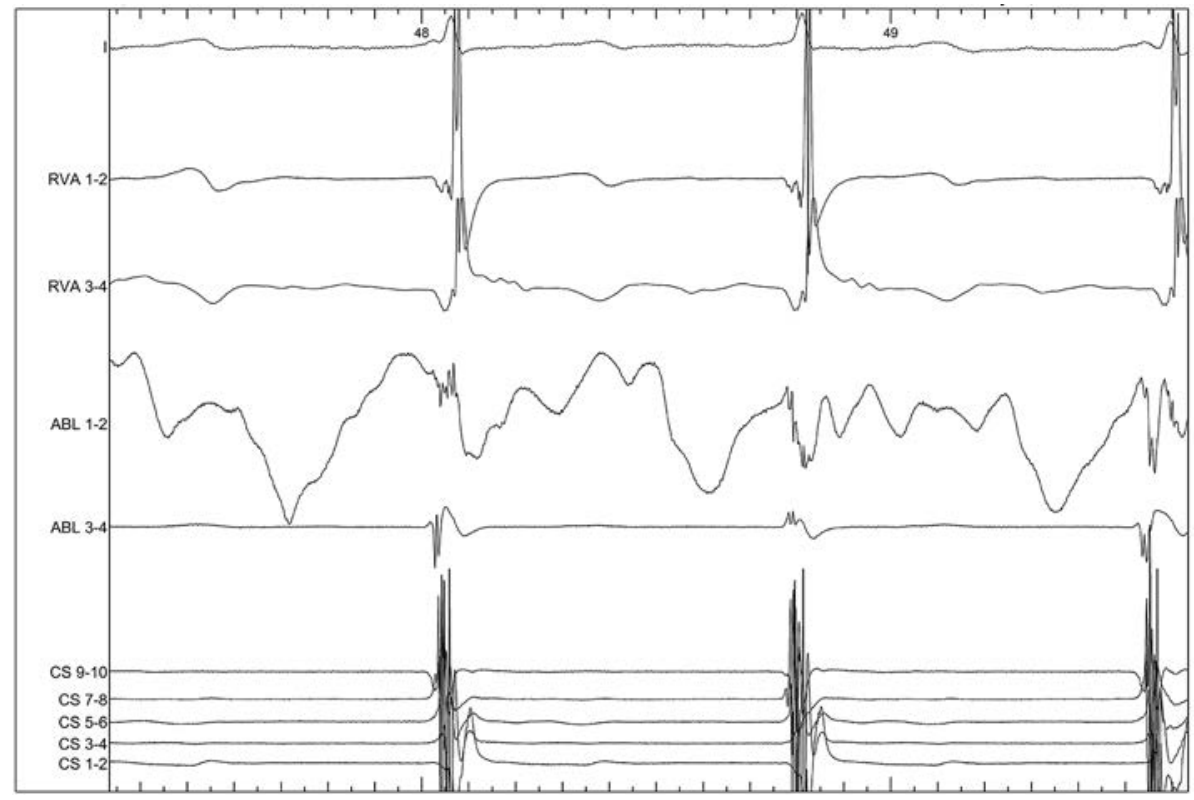

Rycina 5. Zapis wewnątrzsercowy - aplikacja prądu o częstotliwości radiowej (RF, radiofrequency) w miejscu lewostronnej drogi wolnej węzła przedsionkowo-komorowego (AVN, atrioventricular nodal); widoczne wolne pobudzenia węzłowe ze wstecznym przewodzeniem do przedsionków

\section{Abstract}

Ablation of right-sided and left-sided slow pathway of atrioventricular nodal reentrant tachycardia is presented.

Key words: ablation, atrioventricular nodal reentrant tachycardia, left-sided slow pathway

Folia Cardiologica 2017; 12, 5: 497-500

\section{Piśmiennictwo}

1. Katritsis DG, Giazitzoglou E, Zografos T, et al. An approach to left septal slow pathway ablation. J Interv Card Electrophysiol. 2011;
30(1): 73-79, doi: 10.1007/s10840-010-9527-z, indexed in Pubmed: 21153692. 